Reversal of Parkinsonian symptoms in primates by antagonism of excitatory amino acid transmission: Potential mechanisms of action

Mitchell, IJ

http://hdl.handle.net/10026.1/3497

10.1016/s0149-7634(96)00036-x

Neuroscience \&amp; Biobehavioral Reviews

Elsevier BV

All content in PEARL is protected by copyright law. Author manuscripts are made available in accordance with publisher policies. Please cite only the published version using the details provided on the item record or document. In the absence of an open licence (e.g. Creative Commons), permissions for further reuse of content should be sought from the publisher or author. 


\title{
Reversal of Parkinsonian Symptoms in Primates by Antagonism of Excitatory Amino Acid Transmission: Potential Mechanisms of Action
}

\author{
I. J. MITCHELL* AND C. B. CARROLL \\ School of Psychology, University of Birmingham, Birmingham B15 2TT, UK
}

\begin{abstract}
MITCHELL, I.J. AND C.B. CARROLL. Reversal of parkinsonian symptoms in primates by antagonism of excitatory amino acid transmission: potential mechanisms of action. NEUROSCI BIOBEHAV REV 21(4) 469-475, 1997-Parkinsonism is characterised by overactive glutamatergic transmission in the cortico-striatal and subthalamo-medial pallidal pathways. Local blockade of glutamatergic transmission in these pathways can alleviate parkinsonian symptoms. The effectiveness of the treatment, however, is often limited by the simultaneous appearance of unwanted side-effects. These side-effects, including ataxia and dissociative anaesthesia, are particularly problematic when $N$-methyl-D-aspartate (NMDA) antagonists are used. In an attempt to overcome these problems we have attempted to manipulate excitatory amino acid (EAA)-mediated neurotransmission indirectly by targeting the NMDA receptor associated modulatory sites. We review evidence which demonstrates that antagonists for both the NMDA associated glycine and polyamine sites can reverse parkinsonian symptoms when injected intra-cerebrally in both MPTP-treated and bilateral 6-OHDA lesioned marmosets without eliciting unwanted side-effects. We further review preliminary data which suggest that ifenprodil, a polyamine site antagonist, has striking anti-parkinsorian actions in the marmoset. Potential mechanisms of action underlying these effects are discussed in terms of NMDA receptor subtypes and the neuroanatomical locus of action. The anti-parkinsonian efficacy of intra-striatally administered EAA antagonists leads us to question the view of dopamine acting in the striatum as a simple neuromodulator. (C) 1997 Elsevier Science Ltd.
\end{abstract}

Parkinsonism glutamate excitatory amino acid NMDA striatum globus pallidus glycine (R)-HA-966 polyamine ifenprodil kappa opiate primate

\section{THE ROLE OF EAAS IN THE PATHOPHYSIOLOGY OF PARKINSONISM}

THE last 10 years have seen great advances in our understanding of the pathophysiology of parkinsonism. Studics using unit recording $(35,59)$, in situ hybridization (2) and 2deoxyglucose metabolic mapping $(36,47)$ approaches in primate models of parkinsonism have enabled much of the neural circuitry which mediates the motor manifestations of parkinsonism to be mapped (for review see (1)).

This work has pointed to the importance of excess excitatory amino acid (EAA)-mediated transmission in mediating parkinsonian symptoms within two critical neuronal populations within the basal ganglia. The parkinsonian brain is firstly characterised by abnormally high levels of EAA-mediated activity in the projection from the subthalamic nucleus to the medial segment of the globus pallidus. Secondly, striatal neurons are abnormally overactive due to an excess of EAA-mediated corticostriatal transmission. This excess striatal activity is, however, restricted to only one of the subpopulations of striatal output neurons, that is the enkephalin positive striatal neurons which project to the lateral segment of the globus pallidus $(2,17,18,24,49)$. The remainder of the striatal projection neurons are, in contrast, assumed to be abnormally underactive in experimental parkinsonism. These neurons are thought to be the dynorphin-expressing neurons which project directly to the medial segment of the globus pallidus $(18,24)$.

\section{EAA ANTAGONISTS CAN MODIFY PARKINSONIAN SYMPTOMS}

From the physiological studies outlined above it could be hypothesised that reduction of EAA-mediated transmission would alleviate parkinsonian symptoms. Support for such a hypothesis can be found in the literature where EAA antagonists have been administered to parkinsonian rodents and primates by both systemic and intracerebral routes.

MK-801 ( + )-5-methyl-10,11-dihydro-5H-dibenzo[a,d]cyclohept-5,10-imine maleate) (a non-competitive NMDA ( $N$-methyl-D-aspartate) receptor antagonist), has been shown to increase locomotion in monoamine-depleted rodents following systemic injection $(8,9)$ Similarly, systemically administered NBQX (2,3-dihydroxy-6-nitro-7sulfamoyl-benzo-(F) quinoxaline) (an EAA antagonist with selectivity for the AMPA ( $\alpha$-amino-3-hydroxy-5methyl-4-isoxazole propionate) receptor), has been reported 
to decrease parkinsonian symptoms in the MPTP (1-methyl4-phenyl-1,2,3,6-tetrahydropyridine)-treated macaque (26). Others, however, have failed to replicate this effect. For example, Luquin et al. reported a lack of anti-parkinsonian effect of NBQX when systemically administered to MPTPtreated macaques, the drug instead inducing lethargy and myoclonic jerks (31).

Much of our own work has concentrated on investigating the effects of intracerebrally administered EAA antagonists. In these studies we have demonstrated that antagonism of EAA transmission within the medial pallidal segment of the MPTP-treated marmoset using either kynurenic acid (broad spectrum EAA antagonist) or 7-chlorokynurenate (an antagonist at the NMDA-associated glycine site) can result in a dramatic, but temporary, amelioration of parkinsonian symptoms $(6,38)$. Kynurenate was also effective in reversing the motor symptoms of parkinsonism when injected into the medial pallidal segment of the MPTP-treated macaque (19). In related rodent studies we have demonstrated that unilateral intrastriatal injections of both D-CPP (a competitive NMDA receptor antagonist), and (R)-HA966 (1-hydroxy-3-aminopyrrolid-2-one) (a glycine-site partial agonist) can induce locomotion in reserpine-treated and rotation in unilaterally 6-OHDA (6-hydroxydopamine)lesioned rats (10).

\section{POTENTIAL LIMITATIONS OF THE USE OF EAA ANTAGONIST IN THE} TREATMENT OF PARKINSONISM

From the studies mentioned above it is clearly feasible to alleviate parkinsonian symptoms in rodents and primates by either the systemic or intracerebral administration of EAA antagonists, especially those acting at the NMDA receptor. However, the NMDA receptor has a widespread distribution throughout the central nervous system $(33,63)$, reflecting its diverse functions. It might be expected, therefore, that such approaches to the symptomatic relief of parkinsonism will not be without problems, as targeting of specific populations of overactive neurons within the striatum and medial pallidal segment following systemic administration of agents will be extremely difficult.

Processes with which the NMDA receptor is known to be involved include long term potentiation within the hippocampus, possibly associated with memory formation $(12,13)$, neuronal pathway development $(22)$, neurotoxicity (53) and induction of anaesthesia (34). In keeping with these reservations are observations of deficits that result from the pharmacological blockade of NMDA receptors in behavioural studies.

Blockade of NMDA receptors is known to produce deficits in learning and memory $(45,48)$. It has additionally been demonstrated that whilst the systemic administration of MK-801 to monoamine-depleted mice undoubtedly increases locomotion it does so at the cost of inducing ataxia (8). This occurs despite the suggestion that MK-801 might be able to elicit a more specific behavioural effect by binding selectively to overactive NMDA receptors whose channels are open for longer (58).

Further reports suggest that there are species differences in response to systemic NMDA antagonists, such that MK801 fails to exert an anti-parkinsonian action in primates. Thus Crossman et al. (14), reported a failure of MK-801 to improve motor control in MPTP-treated macaques, the drug instead producing a sedative-like effect. Similarly, Domino and Sheng (15) reported a slight effect on rotation behaviour when MK-801 was administered to MPTP-induced hemiparkinsonian macaques, though the animals became cataleptic at higher doses. Equally disappointing results have come from MPTP-treated marmoset studies where MK-801 has failed to reverse parkinsonism but induced ataxia (11). Similarly, competitive NMDA receptor antagonists, such as CGP 40.116, given alone to MPTP-treated marmosets failed to improve motor performance but elicited ataxia (61). Systemic injection of MK-801 in cynomologous monkeys and squirrel monkeys has also been shown to result in sedation and ataxia (54).

Local antagonism of EAA-mediated transmission in parkinsonian rats by injections of either kynurenic acid into the medial pallidal segment (6) or CPP into the striatum (10) also induced side-effects which compromised the antiparkinsonian effects of the manipulations. In these instances the alleviation of parkinsonian symptoms proceeds in a dose related manner until the drug starts to induce sedative effects.

\section{ALTERNATIVE APPROACHES TO THE MANIPULATION OF NMDA-MEDIATED TRANSMISSION}

The above considerations have caused us to explore ways in which NMDA receptor-mediated transmission can be modified in a more selective manner. It is now recognised that there are subtypes of NMDA receptor, each with its own neuroanatomical distribution. This heterogeneity of NMDA receptors can potentially be utilised to target those receptor populations which are abnormally overactive in parkinsonism. In addition, it is known that the different subtypes of NMDA receptor are differentially modulated by agents acting at the various NMDA receptor-associated binding sites, and this may provide further targets for selective pharmacological intervention.

\subsection{Subtypes of NMDA receptors}

There are two main families of subunits for the NMDA receptor. In the rat these are known as NMDA-R1 (44) and NMDA-R2 (28). There are currently known to be at least eight splice variants of the NMDA-R1 subunit $(44,57,62)$ which is thought to contain the agonist binding sites for glutamate and glycine, and is therefore necessary for formation of a functional receptor (62). There are four known NMDA-R2 subunits, A-D, which confer functional diversity on the NMDA receptor complex $(43,23)$. It is thought that most of the functional NMDA receptors in the brain are heteromers, made up of NMDA-R1 and NMDAR2 subunits.

Both the different splice variants of the NMDA-R1 subunit and the different subtypes of NMDA-R2 subunits are reported to display differential regional distribution $(23,43,46,56)$. Indeed the various cell types within the striatum are reported to express different NMDA receptor subunits (30). The different NMDA receptor subunits confer on the receptor different sensitivities to various antagonists, such that NMDA-R2C receptors are most sensitive to 7chlorokynurenate and NMDA-R2A receptors are most sensitive to antagonism by $\mathrm{AP}-5$ and $\mathrm{Mg}^{2+}$ (28). The NMDA-R2A and NMDA-R2B receptor subtypes are sug- 
gested to display differing degrees of modulation by glycine $(39,41)$.

The differential regional distribution of NMDA receptors with different subunit composition may account for the ineffectiveness of intrastriatally injected D-AP-5 in alleviating parkinsonian symptoms in rodents compared with D-CPP and (R)-HA-966 (10). D-AP-5 is known to have low affinity for the 'agonist-preferring' NMDA receptor subtype which contains the NMDA-R2B subunit $(7,28,41)$ which is prevalent in the striatum $(39,56)$.

The polyamine site associated with the NMDA receptor is another potential target for therapeutic intervention. The polyamine-site antagonist, ifenprodil, is thought to be selective for NMDA receptors expressing the NMDA-R2B subunit (60). Thus ifenprodil might be able to exert selective effects on striatal NMDA receptors. Ifenprodil, in contrast to D-CPP, does not affect learning and memory formation in mice (48), suggesting that it might exhibit selectivity for an NMDA receptor subtype when administered systemically.

These differences in the composition of NMDA receptors in specific anatomical locations can thus be potentially exploited in order to achieve selective modulation of NMDA receptor-mediated transmission.

\subsection{NMDA receptor modilatory sites}

It is now well established that transmission at the NMDA receptor-associated ion channel can be modified by the activity at modulatory sites. The diversity and complexity of these modulatory sites of the NMDA receptor may underlie the different functions with which the NMDA receptor is known to be involved. The NMDA receptor complex can be considered to be made up of four domains: the glutamate binding site, the glycine binding site, the polyamine site and the ion channel. Associated with the channel are four negative modulatory binding sites: the magnesium site, the zinc site, the site for protons, and the phencyclidine site for allosteric modulators. These sites not only affect ligand binding to the glutamate site and channel activation, but also interact with each other, resulting in complex modulatory mechanisms $(20,21,51,52,55)$.

Glycine is a co-agonist for the NMDA receptor such that transmission can only take place at this receptor-ionophore complex if glycine is present (25). Recent work on differentiating subtypes of NMDA receptors has suggested that the interactions between the glutamate and glycine sites of the NMDA receptor are complex, such that different subtypes of NMDA receptors show different levels of modulation by glycine (39). This raises the possibility of using glycine-site antagonists to selectively block transmission at a subpopulation of NMDA receptor complexes. Manipulation of NMDA-mediated transmission by exploiting the glycine site is also an attractive possibility due to the availability of glycine-site partial agonists. Such agents, which include (R)-HA-966 (50), could potentially be used to attenuate NMDA receptor-mediated transmission whilst allowing a basal level to continue (16).

\subsection{Indirect modification of EAA-mediated transmission}

The release of EAAs in some brain areas is regulated presynaptically by the action of opiates. This characteristic can be potentially used in order to modify EAA trans- mission indirectly. Within the basal ganglia there are moderate-high densities of kappa opiate receptors. Electrophysiological studies in rat brain have shown that kappa opioid agonists reduce EAA release from presynaptic terminals in globus pallidus and substantia nigra pars reticulata (32). Thus, kappa opiate agonists, such as the neuroprotective agent enadoline (CI-977) can potentially be used to block EAA release in the output structures of the basal ganglia and thus result in the symptomatic relief of parkinsonism.

\section{ANIMAL MODELS OF PARKINSONISM}

Investigations of whether these approaches to modifying EAA-mediated transmission can alleviate parkinsonian symptoms need to be conducted in the first instance in an appropriate animal model. Several animal models of parkinsonism are in routine use, all of which have advantages and limitations. There are concerns that parkinsonian primates may respond differently to rodents following the administration of NMDA receptor antagonists. For example, as cited above, systemically-administered MK-801 increased locomotion in monoamine-depleted mice but has no antiparkinsonian effects in MPTP-treated macaques. Furthermore, we have recently demonstrated that responses to drug treatment in reserpine-treated rodents varies according to the reserpine administration protocol. We have thus shown that a double reserpine procedure, whereby a second dose of reserpine is given after a one week recovery period, changes the anti-parkinsonian efficacy of both dopamine agonists and NMDA receptor antagonists such that the behavioural response seen is much greater after the second dose of reserpine than the first (10). As a consequence of potential species differences of this type and reservations about the reserpine model we have conducted studies in parkinsonian primates where possible.

We have used a novel bilateral 6-OHDA lesioned marmoset model to investigate the possibility of relieving parkinsonian symptoms by manipulation of EAA transmission by the use of glycine-site antagonists, polyamine-site antagonists and kappa opiate agonists. The model is prepared by making lesions of the medial forebrain bundle in a two-stage procedure where the interval between the lesions is two months. This procedure results in a stable, marked parkinsonian condition, which we have extensively characterised, without the occurrence of the major debilitating features normally associated with bilateral 6-OHDA lesions (37). Marmosets treated in this manner have a hunched posture, show very little spontaneous movement, bradykinesia, freezing and difficulty in initiating movements but, with careful husbandry immediately following the second lesion, maintain their body weight to within $90 \%$ of preoperative values. All of these parkinsonian symptoms can be alleviated, in a dose-dependent manner, by the systemic administration of levodopa.

\section{ANTI-PARKINSONIAN EFFECTS OF (R)-HA-966}

We have investigated the potential of the glycine-site partial agonist, (R)-HA-966, to alleviate parkinsonian symptoms in the bilateral 6-OHDA lesioned marmoset (37). (R)HA-966 was injected directly into the marmoset striatum, 
into either the dorsolateral caudate nucleus or the ventromedial putamen. A dose-dependent reversal of parkinsonian symptoms was seen at both anatomical sites, the latency of onset being approximately $5 \mathrm{~min}$. The maximal response was elicited by bilateral injections of $250 \mathrm{nmol}$ (R)-HA-966. At this dose the animals' parkinsonian symptoms were completely alleviated in the absence of stereotypy or anaesthetic-like side-effects, such that motor behaviour was virtually normal. Indeed, intrastriatal injections of the partial glycine agonist were as effective as equivalent injections of the mixed D1/D2 dopamine agonist, apomorphine.

This effect of (R)-HA-966 is similar to that observed in rodent models of parkinsonism. We have demonstrated that equivalent intrastriatal injections of the drug elicit rotation behaviour in unilateral 6-OHDA lesioned rats and increase locomotion in reserpine-treated rats (10). We have further established that this effect can be blocked by the co-administration of the glycine-site agonist, D-serine, which suggests that the anti-parkinsonian effects of (R)-HA-966 are indeed mediated via antagonism of the NMDA receptor-associated glycine site.

(R)-HA-966 can also elicit an anti-parkinsonian action in rodents when injected systemically. Our studies showed a slight alleviation of parkinsonian symptoms following systemic injection of the drug but these increases in mobility diminished with time due to a decrease in muscle tone which began to interfere with purposeful movement (10). Similarly, others have demonstrated that systemically injected (R)-HA-966 can ameliorate haloperidol-induced catalepsy (27).

Disappointingly, we found no evidence to suggest that (R)-HA-966 has an anti-parkinsonian action when systemically administered to bilateral 6-OHDA lesioned marmosets. Injections in the dose range $50-300 \mathrm{mg} \mathrm{kg}^{-1}$ (i.m.) had no effect on movement, with the exception of occasional stereotyped scratching movements, nor did they elicit any sedative or anaesthetic-like effects (37). It is not clear why (R)-HA-966 should be active when injected into the striatum and not when administered systemically, however it could reflect inability of this water-soluble compound to cross the blood-brain barrier in the primate.

The absence of a sedative response seen after intrastriatal or systemic injection of (R)-HA-966 is in sharp contrast to the marked anaesthetic-like side-effects following both central and systemic injections of MK-801, D-CPP and kynurenic acid. One possible explanation for the difference in response is that (R)-HA-966 is acting as a partial agonist in contrast to these other agents which act as NMDA receptor antagonists. (R)-HA-966 would thus be expected to allow a certain amount of NMDA-mediated transmission to take place which could presumably be sufficient to prevent the onset of sedation or anaesthesia. This explanation, attractive in its simplicity, however, -cannot account for some of our preliminary data on the action of 7-chlorokynurenate. This drug, a full glycine-site antagonist, alleviates parkinsonian symptoms when injected into the medial pallidal segment of the globus pallidus in the MPTP-treated marmoset in the absence of any side-effects (38). An alternative explanation of the efficacy of glycine-site antagonists in alleviating parkinsonian symptoms may lie in the ability of glycine to differentially modulate glutamate binding and activity at different subtypes of the NMDA receptor $(39,40)$ reflecting different NMDA-R2 subunit composition.
7. ANTI-PARKINSONIAN EFFECTS OF ANTAGONISM OF THE NMDA RECEPTOR-ASSOCIATED POLYAMINE SITE

We have shown that systemic administration of the NMDA receptor-associated polyamine site antagonist, ifenprodil, can exert a dramatic alleviation of parkinsonian symptoms in the bilateral 6-OHDA lesioned marmoset. A dose of $12.5 \mathrm{mg} \mathrm{kg}^{-1}$ of ifenprodil (i.m.) resulted in short latency $(10 \mathrm{~min}$ ) and long duration (over $3 \mathrm{~h}$ ) alleviation of parkinsonian symptoms. The animals' motor behaviour did not fully return to normal, which may indicate that this dose was not optimal. The drug, however, did not elicit any signs of sedation, anaesthesia, stereotypy or ataxia. It is also encouraging to note that ifenprodil, when systemically administered to rodents, does not impair working memory as measured by alteration behaviour in a Y-maze (48).

Less encouraging with respect to the potential of polyamine site antagonists to alleviate parkinsonian symptoms in human patients is a brief clinical paper which fails to report significant anti-parkinsonian effects following administration of ifenprodil (42). The authors of this paper, however, emphasise both its preliminary nature and the potential problems of dose and/or pharmacokinetics of ifenprodil.

\section{ANTI-PARKINSONIAN EFFECTS OF KAPPA OPIOID AGONISTS}

We have investigated the potential of the kappa opiate agonist, enadoline (CI-977) in alleviating parkinsonian symptoms in both rats and marmosets. We initially demonstrated that enadoline could increase mobility when injected into the medial pallidal segment of the MPTP-treated marmoset and the entopeduncular nucleus (the rodent homologue of the primate medial pallidal segment) of the reserpine-treated rat (32). The presumed mechanism of action mediating these antiparkinsonian responses is binding of enadoline to presynaptic kappa opiate receptors on the terminals of the subthalamic nucleus neurons which project to the medial pallidal segment thereby blocking EAA release.

More recently, we have shown that systemically injected enadoline can alleviate parkinsonian symptoms in the bilateral 6-OHDA lesioned marmoset (37). Injections of $7.5 \mathrm{mg} \mathrm{kg}^{-1}$ (i.m.) resulted in a response with short latency (approximately $5 \mathrm{~min}$ ) and duration of approximately $40 \mathrm{~min}$. This manipulation, however, failed to return the animals' behaviour completely to normal. The marmosets did show periods of normal behaviour but these were interrupted by bouts of slow repetitive jumping which were accompanied by a loss of co-ordination. These limited effects of enadoline in alleviating parkinsonism could be blocked by the co-administration of both naloxone, a broad spectrum opiate antagonist, and nor-binaltorphimine (norBNI), a specific kappa opiate antagonist.

\section{POTENTIAL MECHANISMS OF ACTION OF EAA ANTAGONISTS IN REVERSING PARKINSONIAN SYMPTOMS}

From the brief review of the literature outlined above it is clear that blockade of EAA-mediated transmission using selective antagonists can alleviate parkinsonian symptoms in primates. Careful selection of the agent to be used may result in production of the desirable effect in the absence of side-effects. The mechanism by which these agents exert their anti-parkinsonian effects can be 
discussed at several levels including the neuroanatomical site of action and the effect on information processing within the basal ganglia as well as the pharmacological mode of action.

It is clearly possible to alleviate parkinsonian symptoms in both the MPTP-treated marmoset and the bilateral 6OHDA lesioned marmoset by making local injections of EAA antagonists into either the medial segment of the globus pallidus or the striatum. These findings are entirely in keeping with the model of the pathophysiology of parkinsonism that we and others have advanced. This model argues that: (1) parkinsonian symptoms arise as a result of abnormally high rates of discharge in the striatal neurons which project to the lateral segment of the globus pallidus, and (2) these abnormal discharges result from excess of EAA-mediated transmission in the afferents to these neurons. It is not possible, on the basis of the data reviewed here, to determine the neuroanatomical site of the anti-parkinsonian action of ifenprodil when injected systemically. The most likely candidates would, however, be the striatum and the medial pallidal segment.

The effect of local manipulation of EAA transmission within the medial segment of the globus pallidus also parallels the effects of surgical ablation of basal ganglia structures in both idiopathic parkinsonian patients and experimental animals. It has thus been demonstrated that selective destruction of the medial pallidal segment, which by definition must decrease the discharge rate of its neurons, alleviates parkinsonian symptoms (29). Similarly, lesions of the subthalamic nucleus, which provide the EAA input to the medial pallidal segment, also result in symptomatic relief (4). These effects can also be achieved in a reversible manner using high frequency stimulation which leads to a depolarisation blockade (3).

Some researchers have argued that dopamine replacement therapy is capable of alleviating parkinsonian symptoms because dopamine acts in a neuromodulatory manner (5). Dopaminergic neurons in the nigrostriatal path- way are thus seen as forming a modulatory system within the brain which does not normally convey specific, temporally or spatially patterned messages. If dopamine does act in a neuromodulatory manner then dopamine replacement therapy for the treatment of parkinsonism can function without the need to activate striatal dopamine receptors in a precise spatial and temporal manner. Rather, systematically administered dopamine agonists could just bathe the striatal dopamine receptors, which, provided the dose was in the correct range, would allow the complex ordered message from the cerebral cortex to once more cause the striatal projection neurons to discharge in an appropriate manner and thus alleviate parkinsonian symptoms. According to these intuitions it should not be possible to alleviate parkinsonian symptoms by antagonising EAA transmission within the striatum as this would eradicate, or at least severely disrupt, the cortical message being sent to the striatum. The observation that local injection of (R)-HA966 into the striatum reverses parkinsonian symptoms is hard to reconcile with this view of the functional organisation of the striatum. Thus, the local application of the NMDA receptor-associated glycine-site partial agonist must exert its anti-parkinsonian effect by blocking the complex highly structured, spatially and temporally organised cortical input.

\section{OVERVIEW}

In summary, it is clear that EAA antagonists can be used to reverse parkinsonian symptoms in parkinsonian primates. The propensity of these antagonists to induce side-effects such as sedation and ataxia can be potentially overcome by using more selective antagonists such as the polyamine-site antagonist, ifenprodil. The ability of ifenprodil to alleviate parkinsonism in the bilateral 6-OHDA lesioned marmoset is particularly promising and there is a pressing need to investigate the potential anti-parkinsonian properties of related compounds.

\section{REFERENCES}

1. Albin, R. L.; Young, A. B.; Penney, J. B., The functional anatomy of basal ganglia disorders. Trends in Neurosciences, 12, 366-375 1989.

2. Augood, S. J.; Emson, P. C. et al., Cellular localisation of enkephalin gene expression in MPTP-treated cynomologous monkeys. Molecular Brain Research, 6, 85-92 1989.

3. Benazzouz, A.; Gross, C.; Feger, J.; Boraud, T.; Biolac, B., Reversal of rigidity and improvement in motor performance by subthalamic highfrequency stimulation in MPTP-treated monkeys. Eur. J. Pharmacol., 5, 382-389 1993.

4. Bergman, H.; Wichmann, T.; Delong, M. R., Reversal of experimental parkinsonism by lesions of the subthalamic nucleus. Science, 249, 1436-1438 1990.

5. Bjorklund, A.; Lindvall, O.; Isacson, O.; Brudin, P.; Wictorin, K.; Streker, R. E.; Clarke, D. J.: Dunnett, S. B., Mechanisms of action of intracerebral neural transplants: studies on nigral and striatal grafts to the lesioned striatum. Trend's in Neurological Sciences, 10, 509-516 1987.
6. Brotchie, J. M.; Mitchell, I. J.; Sambrook, M. A.; Crossman, A. R., Alleviation of parkinsonism by antagonism of excitatory amino acid transmission in the medial segment of the globus pallidus in rat and primate. Movement Disoders, 6 (2), 133-138 1991.

7. Buller, A. L.; Morrisett, R. A.; Monaghan, D. T. The NR2 subunit contributes to the pharmacological diversity of native NMDA receptors. Soc. Neurosci. Abstr., 19(2): 1356, 557.10; 1993.

8. Carlsson, M.; Carlsson, A., The NMDA antagonist MK-801 causes marked locomotor stimulation in monoamine-depleted mice. Journal of Neural Transmission, 75, 221-2261989.

9. Carlsson, M.; Carlsson, A., Dramatic synergism between MK-801 and clonidine with respect to locomotor stimulatory effect in monoaminedepleted mice. Journal of Neural Transmission, 77, 65-71 1989.

10. Carroll, C. B.; Holloway, V.; Brotchie, J. M.; Mitchell, I. J., Neurochemical and behavioural investigations of the NMDA receptor-associated glycine site in the rat striatum: functional implications for treatment of parkinsonian symptoms. Psychopharmacology, 119, 55-65 1995. 
11. Close, S. P.; Elliott, P. J. et al., Effects of classical and novel agents in a MPTP-induced reversible model of Parkinson's disease. Psychopharmacology, 102, 295-300 1990.

12. Collingridge, G. L.; Bliss, T. V. P., NMDA receptors-their role in longterm potentiation. Trends in Neurosciences, 10 (7), 288-293 1987

13. Collingridge, G. L.; Singer, W., Excitatory amino acid receptors and synaptic plasticity. Trends in Pharmacological Sciences, 11, 290-296 1990.

14. Crossman, A. R.; Peggs, D. et al., Effect of the NMDA antagonist MK801 on MPTP-induced parkinsonism in the monkey. Neuropharmacology, 28 (11), 1271-1273 1989.

15. Domino, E. F.; Sheng, J., NMDA antagonist and dopamine D-1 and D 2 agonist interactions in MPTP-induced hemiparkinsonian monkeys. Journal of Pharmacological and Experimental Therapy, 264, 221-225 1993.

16. Foster, A. C.; Kemp, J. A., HA-966 antagonizes N-methyl-D-aspartate receptors through a selective interaction with the glycine modulatory site. Journal of Neuroscience, 9 (6), 2191-2196 1989.

17. Frayne, S. E.; Mitchell, I. J. et al., Distribution of enkephalin gene expression in the striatum of the parkinsonian primate: implications for dopamine agonist-induced dystonia. Molecular Neuropharmacology, 1, 53-58 1991.

18. Gerfen, C. R.; McGinty, J. F.; Young, W. S., Dopamine differentially regulates dynorphin, substance $P$, and enkephalin expression in striatal neurons: in situ hybridization histochemical analysis. Journal of Neuroscience, 11 (4), 1016-1031 1991.

19. Graham, W. C.; Robertson, R. G.; Sambrook, M. A.; Crossman, A. R. Injection of excitatory amino acid antagonists into the medial pallidal segment of a 1-methyl-4-phenyl-1,2,3,6-tetrahydropyridine (MPTP) treated primate reverses motor symptoms of parkinsonism. Life Sciences 47: PL-91-PL-N97; 1990.

20. Grimwood, S.; Wilde, G. J. C.; Foster, A. C., Interactions between the glutamate and glycine recognition sites of the $\mathrm{N}$-methyl-D-aspartate receptor from rat brain, as revealed from radioligand binding studies. Journal of Neurochemistry, 60, 1729-1738 1993.

21. Grimwood, S.; Struthers, L.; Foster, A. C., Polyamines modulate $\left[{ }^{3} \mathrm{H}\right] \mathrm{L}-689,560$ binding to the glycine site of the NMDA receptor from rat brain. European Journal of Pharmacology, 266, 43-50 1994.

22. Hattori, H.; Wasterlain, C. G., Excitatory amino acids in the developing brain: ontogeny, plasticity, and excitotoxicity. Pediatric Neurology, 6, 219-228 1990.

23. Ishii, T.; Moriyoshi, K. et al., Molecular characterization of the family of the N-methyl-D-aspartate receptor subunits. Journal of Biological Chemistry, 268 (4), 2836-2842 1993.

24. Jiang, H.-K.; McGinty, J. F.; Hong, J. S., Differential modulation of striatonigral dynorphin and enkephalin by dopamine receptor subtypes. Brain Research, 507, 57-64 1990.

25. Kleckner, N. W.; Dingledine, R., Requirement for glycine in activation of NMDA receptors expressed in Xenopus oocytes. Science, 241, 8358361988.

26. Klockgether, T.; Turski, L. et al., The AMPA receptor antagonist NBQX has antiparkinsonian effects in monoamine-depleted rats and MPTP-treated monkeys. Annals of Neurology, 30, 717-723 1991.

27. Kretschmer, B. D.; Winterscheid, B.; Danysz, W.; Schmidt, W. J. Glycine site antagonists abolish D2 but not D1 receptor mediated catalepsy in rats. Journal of Neural Transmission, 95, 123-136 1992.

28. Kutsuwada, T.; Kashiwabuchi, N.; Mori, H. et al., Molecular diversity of the NMDA receptor channel. Nature, 358, 36-41 1992.

29. Laitinen, L. V.; Bergenheim, A. T.; Hariz, M. I., Leksell's posteroventral pallidotomy in the treatment of Parkinson's disease. Journal of Neurosurgery, 76, 53-61 1992

30. Landwehrmeyer, G. B.; Standaert, D. G.; Testa, C. M.; Penney, J. B. Young, A. B. NMDA receptor subunit mRNA expression by projection neurons and interneurons in rat striatum. Joumal of Neuroscience, 15(7 Pt 2):5297-5307; 1995.

31. Luquin, M. R.; Obeso, J. A. et al., The AMPA receptor antagonist NBQX does not alter the motor response induced by selective dopamine agonists in MPTP-treated monkeys. European Journal of Pharmacology, 235, 297-300 1993.

32. Maneuf, Y.; Mitchell, I. J.; Crossman, A. R.; Woodruff, G. N.; Brotchie, J. M., Functional implications of kappa opiate receptor mediated modulation of glutamate transmission in the output regions of the basal ganglia in rodent and primate models of Parkinson's disease. Brain Research, 683, 102-108 1995.
33. Maragos, W. F.; Penney, J. B.; Young, A. B., Anatomic correlation of NMDA and ${ }^{3}$ H-TCP-labeled receptors in rat brain. Journal of Neuroscience, 8, 493-501 1988.

34. Martin, D. C.; Abraham, J.E.; Plagenhof, M.; Aronstam, R.S., Volatile anesthetics and NMDA receptors, Enflurane inhibition of glutamatestimulated $\left[{ }^{3} \mathrm{H}\right] \mathrm{MK}-801$ binding and reversal by glycine. Neuroscience Letters, 132, 73-76 1991.

35. Miller, W. C.; Delong, M. R. Altered tonic activity of neurons in the globus pallidus and subthalamic nucleus in the primate MPTP model of parkinsonism. In: Carpenter, M. B.; Jayaraman A., eds. Advances in behavioral biology, 32. The basal ganglia II. Structure and functioncurrent concepts. New York: Plenum Press; 1987:395-403.

36. Mitchell, I. J.; Clarke, C. E. et al., Neural mechanisms underlying parkinsonian symptoms based upon regional uptake of 2-deoxyglucose in monkeys exposed to 1-methyl-4-phenyl-1,2,3,6-tetrahydropyridine. Neuroscience, 32, 213-226 1989.

37. Mitchell, I. J.; Hughes, N.; Carroll, C. B.; Brotchie, J. M. B., Reversal of parkinsonian symptoms by intrastriatal and systemic manipulations of EAA and dopamine transmission in the bilateral 6-OHDA lesioned marmoset. Behavioral Pharmacology, 6, 492-508 1995.

38. Mitchell, I. J.; Brotchie, J. M; Cooper, A. J.; Crossman, A. R., Reversal of parkinsonism by antagonism of excitatory amino acid transmission in the medial segment of the globus pallidus in the primate. European Journal of Neuroscience, 4 (suppl.), 40501990.

39. Monaghan, D. T.; Olverman, H. J.; Nguyen, L.; Watkins, J. C.; Cotman, C. W., Two classes of $N$-methyl-D-aspartate recognition sites: differential distribution and differential regulation by glycine. Proceedings of the National Academy of Sciences USA, 85, 983698401988.

40. Monaghan, D. T., Differential stimulation of $\left[{ }^{3} \mathrm{H}\right]+801$ binding to subpopulations of NMDA receptors. Neuroscience Letters, 122, 21 241991.

41. Monaghan, D. T.; Clark, H. C.; Schneider, B. E. Distributions of NMDA receptor subtypes correspond to specific receptor subunits. Soc. Neurosci. Abstr., 19(2): 1356, 557.9; 1993.

42. Montastruc, J. L.; Rascol, O. et al., A pilot study of N-methyl-Daspartate (NMDA) antagonist in Parkinson's disease. Journal of Neurology, Neurosurgery and Psychiatry, 85 (7), 630-631 1992.

43. Monyer, H.; Sprengel, R. et al., Heteromeric NMDA receptors: molecular and functional distribution of subtypes. Science, 256, 1217-1221 1992.

44. Moriyoshi, K.; Masu, M. et al., Molecular cloning and characterization of the rat NMDA receptor. Nature, 354, 774-776 1991

45. Morris, R. G. M.; Anderson, E.; Lynch, G. S.; Baudry, M., Selective impairment of learning and blockade of long-term potentiation by an N-methyl-D-aspartate receptor antagonist, AP-5. Nature, 319, 7747761986

46. Nakanishi, N.; Axel, R.; Schneider, N. A., Alternative splicing generates functionally distinct N-methyl-D-aspartate receptors. Proceedings of the National Academy of Sciences USA, 89, 8552-8556 1992.

47. Palombo, E.; Perrino, L. J.; Bankiewski, K. S. et al., Local cerebral glucose utilization in monkeys with hemiparkinsonism induced by intracerebral infusion of the neurotoxin MPTP. Journal of Neuroscience, 10 (3), 860-8691990.

48. Parada, J.; Czuczwar, S. J.; Turski, W. A., NBQX does not affect learning and memory tasks in mice: a comparison with D-CPPene and ifenprodil. Cognitive Brain Research, 1, 67-71 1992.

49. Pollack, A. E.; Wooten, G. F., Differential regulation of striatal preproenkephalin mRNA by D1 and D2 dopamine receptors. Molecular Brain Research, 12, 111-119 1992.

50. Pullan, L. M.; Verticelli, A. M.; Paschetto, K. A., Agonist-like character of the (R)-enantiomer of 1-hydroxy-3-amino-pyrroli-2-one (HA-966). European Journal of Pharmacology, 208, 25-29 1991.

51. Reynolds, I. J., Minireview: modulation of NMDA receptor responsiveness by neurotransmitters, drugs and chemical modification. Life Sciences, 47, 1785-1792 1990.

52. Reynolds, R. J.; Miller, R. J., Allosteric modulation of NMDA receptors. Advances in Pharmacology, 21, 101-1261990.

53. Rothman, S. M.; Olney, J. W., Excitotoxicity and the NMDA receptor. Trends in Neurosciences, 10 (7), 299-302 1987.

54. Rupniak, N. M.; Boyce, S.; Tye, S.; Cook, G.; Iversen, S. D., Anxiolytic-like and antinociceptive effects of MK-801 accompanied by sedation and ataxia in primates. Pharmacology and Biochemistry of Behavior, 44 (1), 153-156 1993.

55. Scatton, B., The NMDA receptor complex. Fundamentals of Clinical Pharmacology, 7, 389-400 1993. 
56. Standaert, D. G.; Testa, C. M.; Young, A. B.; Penney, J. B., Organization of N-methyl-D-aspartate glutamate receptor gene expression in the basal ganglia of the rat. Journal of Comparative Neurology, 343, $1-161994$.

57. Sugihara, H.; Moriyoshi, K. Structure and properties of seven isoforms of the NMDA receptor generated by alternative splicing. Biochemical and Biophysical Research Communications 185(3): 826-832.6; 1992.

58. Uematsu, D.; Greenberg, J. H. et al., Mechanism underlying protective effect of MK-801 against NMDA-stimulated neuronal injury in vivo. Journal of Cerebral Blood Flow and Metabolism, 11, 779-785 1991.

59. Wichmann, T.; Bergman, H.; DeLong, M. R., Increased neuronal activity in the subthalamic nucleus (STN) of MPTP treated monkeys. Movement Disorders, 5, 781990.
60. Williams, K.; Russell, S. L. et al., Developmental switch in the expression of NMDA receptors occurs in vivo and in vitro. Neuron, 10, 267-278 1993.

61. Wullner, U.; Kupsh, A.; Arnold, G.; Renner, P.; Scheid, C.; Scheid, R.; Oertel, W.; Klockgether, T., The competitive NMDA antagonist CGP 40116 enhances L-DOPA response in MPTP-treated marmosets. Neuropharmacology, 31, 713-715 1992.

62. Yamazaki, M.; Mori, H. et al., Cloning, expression and modulation of a mouse NMDA receptor subunit. FEBS, 300, 39-45 1992.

63. Young, A. B.; Dauth, G. W.; Hollingsworth, Z.; Penney, J. B.; Kaatz, K.; Gilman, S., Quisqualate- and NMDA-sensitive $\left[{ }^{3} \mathbf{H}\right]$ glutamate binding in primate brain. Journal of Neuroscience Research, 27 (4), 512-521 1990. 